\title{
Translation and Psychometric Properties of the Persian Version of the Dialysis Symptom Index in Hemodialysis Patients
}

\author{
Hadi Zamanian ${ }^{1}$; Zahra Taheri Kharameh ${ }^{2, *}$ \\ ${ }^{1}$ Department of Health Education and Promotion, School of public health, Tehran University of Medical Sciences, Tehran, IR Iran \\ ${ }^{2}$ School of Paramedical Sciences, Qom University of Medical Sciences, Qom, IR Iran \\ *Corresponding author: Zahra Taheri Kharameh, School of Paramedical Sciences, Qom University of Medical Sciences, Qom, IR Iran. Tel: +98-9354024468, E-mail: ztaheri@muq.ac.ir
}

Received: August 30, 2014; Revised: October 3, 2014; Accepted: October 26, 2014

\begin{abstract}
Background: Hemodialysis patients have a high physical and psychosocial symptom burden. There is no valid and reliable tool for assessing symptoms of hemodialysis patients in Iran.

Objectives: The aim of this study was to determine psychometric properties of the Persian version of the dialysis symptom index (DSI). Patients and Methods: The forward-backward procedure was applied to translate the DSI from English into Persian (Iranian language). The scale (Persian Version) was tested with a convenience sample of 95 patients with end-stage renal disease referred to main hemodialysis centers from December 2012 to June 2013. Validity was assessed using content, face and convergent validity. To test reliability, the kappa values were calculated for test-retest stability and the Cronbach alpha coefficients were also calculated for internal consistency.

Results: The mean age of patients was 50.4 ( $\mathrm{SD}=15.72$ ) years and \% 61.1 of patients were male. The most commonly reported symptoms were fatigue, being irritable and nervous. Divergent validity was mostly supported by the pattern of association between DSI and SF-36 ( $r$ $=-0.18--0.48, \mathrm{P}<0.05)$. Cronbach's alpha of the DSI was 0.90 and the weighted kappa ranged from 0.21 to 0.93 , and it was greater than 0.4 for 25 of the 30 items.

Conclusions: The Iranian version of the DSI had good psychometric properties and can be used to assess symptoms of hemodialysis patients.
\end{abstract}

Keywords:Dialysis; Hemodialysis; Patients

\section{Background}

End-stage renal disease (ESRD) is an important health problem worldwide (1). In Iran, the prevalence and incidence rates of ESRD increased from 49.9 cases per million people in 2000 to 63.8 cases per million people in 2006 , an almost $28 \%$ increase over six years (2). Hemodialysis patients have several physical and psychosocial symptoms due to comorbid illness, treatment related side effects, lifestyle alteration and psychosocial impact of living with ESRD (3). For example, arecent study demonstrated that all patients experienced degrees of fatigue, which commonly results from anemia of renal failure, and 30.7\% of participants experienced a high level of fatigue (4). In total, $47 \%$ of patients with ESRD experience pain (5) and this can be moderate to severe in $82 \%$ (6). Almost two of every five dialysis patients experience sleep disturbances, and $38 \%$ to $45 \%$ have some degrees of anxiety (5). Other symptoms that occur commonly in hemodialysis populationinclude loss of energy, exhaustion, muscle cramps, anorexia, nausea, pruritus, shortness of breath, sexual inadequacy and restless legs $(6,7)$. Although patients undergoing hemodialysis, as a maintenance invasive treatment, can live longer (8), they have impaired quality of life (QoL) (9-11). Physical and emotional symptoms play an important role in this impairment (12-14). Despite the fact, recent data suggest that nephrologists may not be aware of many of symptoms bothering hemodialysis patients (15). Little is known about the prevalence, severity, and overall impact of physical and psychological symptoms in this population in Iran because of lack of a validated symptom assessment instrument. Therefore, there is a need for a disease specific instrument to assess symptoms of hemodialysis patients accurately. Such an instrument would be helpful both for research and practice purposes and to improve care of dialysis patients. The Dialysis Symptom Index (DSI) is a self- reported index, developed by Weisbord et al. which assesses symptoms and their severity in patients with end-stage renal disease (16). It has been used widely in different studies $(2,17,18)$. As the original scale is in English, validation of the Persian version isnecessary.

\section{Objectives}

There is no valid and reliable tool to assess symptoms of hemodialysis patientsin Iran. For this reason, we conducted this study to translate and assess the validity and reliability of the Persian version of DSI. 


\section{Patients and Methods}

\subsection{Design and Patients}

This was a psychometric study conducted from December 2012 to June 2013 in Qom, Iran. A group of ESRD patients referred to main hemodialysis centers were selected via convenience sampling method. Inclusion criteria were aged 15 and older, a hemodialysis history of more than six months without previous transplantation, and having no previous psychiatric disease or psychoactive medicine use. Patients were asked to complete the study questionnaires. If the patients were illiterate, the researcher read the questionnaire items to patients and recorded their responses.

\subsection{Instruments}

The dialysis symptom index (DSI) was used to assess the presence and severity of symptoms. DSI contains 30 items; each targets a specific physical or emotional symptom in hemodialysis patients. We asked patients to report which of 30 individual symptoms had been present over the past week by responding "yes" or "no". For present symptoms, the patient was asked to describe the severity of symptom on a 5-point Likert scale ranging from zero to four. Zero means that a symptom is not bothersome and four reflects a very bothersome symptom. An overall symptom burden score was formulated by summing the number of symptoms. Using this scoring, an overall symptom-severity score ranging from 0 if none of the 30 symptoms was present to 150 if all the 30 symptoms were reported and rated as "bothers very" (16). The Short Form 36 (SF-36) used for assessing the divergent validity is a general health outcome instrument. It has eight subscales including physical functioning, bodily pain, general health, vitality, social functioning, role limitations due to physical problems, role limitations due to emotional problems and mental health. The physical component summary and the mental component summary scores were computed from the scores of these eight domains. Scores in each scale ranged from zero to 100 , with zero representing the worst QoL and 100 representing the best possible score. It has been reported that the original and Persian version of this questionnaire have good reliability and construct validity $(19,20)$. In addition, information about demographic and clinical variables such as age, marital status, educational status, employment, and economic status, comorbidity, smoking, duration and number of hemodialysis were obtained.

\subsection{Translation Procedures}

After receiving permission from the instrument owner, Steven D. Weisbord, for the translation and adaptation of the DSI to Persian, the instrument was translated using the forward-backward method (21). The instrument was translated from English to Persian by two professional translators and the primary Persian version of the questionnaire was developed based on the comparison of the two translations. Next, the Persian version was backtranslated to English by two professional translators who had never seen the original version before. The original and back-translated versions were compared item by item and a final Persian version of the scale was reached.

\subsection{Content Validity}

Content validity is experts' judgment about how much the developed questionnaire covers the content of the intended construct (22). To test the content validity of the scale, a multidisciplinary panel was developed including two nephrologists, four nursing instructors at a university nursing school and four clinical nurses who were working in the dialysis centers. They were asked to comment on reasonability, suitability, attractiveness and logical sequence of items as well as conciseness and comprehensiveness of the questionnaire.

\subsection{Face Validity}

Face validity is the lay people's judgment about the understandability and the general appearance of the instrument (22). Moreover, to assess the questionnaire's face validity, it was given to 10 hemodialysis patients to test its comprehensibility and legibility. According to the presented comments and perspectives by experts and participants, few items of the instrument were slightly simplified and modified.

\subsection{Divergent Validity}

Divergent validity is an approach to assess the construct validity of an instrument demonstrating that an instrument does not correlate too strongly with variables intended to indicate different traits than mentioned items of the instrument. Correlation coefficients between measures of a construct in an instrument and the measures of conceptually different construct of the other instruments are usually given as evidence of divergent validity. If the correlations are negatively low to moderate, the measure has divergent validity (23). In this study, divergent validity was evaluated comparing health status outcome using the SF-36.

\subsection{Ethical Considerations}

Permission to use the original DSI was obtained from the original author, Steven D. Weisbord. The study research proposal was approved by the deputy of research, Qom University of Medical Sciences. Ethical approval was granted by the Medical Ethics Committee, Qom University of Medical Sciences. Participants were free to leave the study at any time without having any effect on their treatment process. The participants were provided with information about the study process. Those who voluntarily agreed to participate in this study signed awritten informed consent. 


\subsection{Data Analysis}

Participants' characteristics and score of each domain of the DSI were analyzed using descriptive statistics. To assess the divergent validity of the DSI, Pearson's correlation coefficient between the scores of the DSI and SF-36 was computed. Internal consistency of the DSI was assessed by computing Cronbach's alpha. Cronbach's $\alpha$ coefficient of 0.7 or above was considered as satisfactory. Testretest reliability was assessed by computing the kappa value of each item. The time interval for this assessment was from one week in this study. A kappa value of $<0.20$ is considered slight, $\leq 0.40$ is fair, $\leq 0.60$ is moderate and $\leq 0.80$ is almost perfect (22). $\mathrm{P}<0.05$ was considered statistically significant.

\section{Results}

In all, 120 patients with ESRD were selected. Of these 95 individuals agreed to participate in the study (response rate $79.1 \%)$. The mean age of patients was $50.4(\mathrm{SD}=15.72)$ years and 61.1 percent of patients were male. Most patients (76.8) were married. The time on hemodialysis was 37.83 (SD=39.14) months. Participants "characteristics are shown in Table 1 . The most commonly reported physical symptoms were fatigue, muscle cramps and itching. Feeling irritable, nervous and worrying were the most common psychosocial symptoms. On an average patients had 18.19 of the 30 symptoms and the mean of symptom severity score was 98.85 ( $S D=23.77$ ) (the range of variation between 30 and 150). About $85.3 \%$ of patients reported degrees of fatigue and $77.9 \%$ of them reported feeling irritable. The divergent validity of the DSI was demonstrated by a significant negative correlation but small-tomoderate between the DSI and SF-36 $(r=-0.18--0.48, \mathrm{P}<$ $0.05)$. The correlations between DSI and SF-36 total and subscales scores are presented in Table 2. Cronbach's alpha for internal consistency reliability was 0.90. For the test-retest reliability, the kappa value ranged between 0.21 and 0.93 . Table 3 shows the test retest reliability of the original and Persian DSI.
Table 1. Clinical and Socio-Demographic Information of the Sample $(\mathrm{N}=95)^{\mathrm{a}}$

\begin{tabular}{lc}
\hline & Results \\
\hline Age, $y$ & $50.40 \pm 15.72$ \\
Gender & \\
Male & $58(61.1)$ \\
Female & $37(38.9)$
\end{tabular}

\section{Educational status}

$\begin{array}{lc}\text { Illiterate } & 30(31.5) \\ \text { Primary school } & 30(31.5) \\ \text { High school } & 28(29.4) \\ \text { Secondary school } & 7(7.6) \\ \text { Marital status } & \end{array}$

\section{Marital status}

Single

$12(12.6)$

Married $73(76.8)$

Divorced/widowed

$10(10.6)$

\section{Employment status}

Employed

Unemployed/housewife

74 (77.9)

\section{Accommodation}

$\begin{array}{cc}\text { Urban } & 88(92.6) \\ \text { Rural } & 7(3.4)\end{array}$

Comorbidity disease

Yes

No

$40(42.1)$

Smoking status

$\begin{array}{lc}\text { Smoker } & 16(16.8) \\ \text { Non-smoker } & 79(83.2) \\ \text { Time on dialysis, mo } & 37.83 \pm 39.14 \\ \text { Dialysis Frequency, N weekly } & 2.92 \pm 0.30\end{array}$

${ }^{\mathrm{a}}$ Data are presented as No. (\%) or Mean \pm SD.

\begin{tabular}{lccc}
\hline Table 2. Correlation Between the Dialysis Symptom Indexand SF-36 for Divergent Validity & \\
\hline Variable & Physical Symptom & Psychological Symptom & Total Dialysis Symptom Index \\
\hline Physical function & $-0.30^{\mathrm{a}}$ & $-0.18^{\mathrm{b}}$ & $-0.26^{\mathrm{b}}$ \\
Role physical & $-0.37^{\mathrm{a}}$ & $-0.41^{\mathrm{a}}$ & $-0.41^{\mathrm{a}}$ \\
Bodily pain & $-0.26^{\mathrm{a}}$ & $-0.32^{\mathrm{a}}$ & $-0.30^{\mathrm{a}}$ \\
General health & $-0.24^{\mathrm{b}}$ & $-0.28^{\mathrm{a}}$ & $-0.27^{\mathrm{a}}$ \\
Vitality & $-0.28^{\mathrm{a}}$ & $-0.41^{\mathrm{a}}$ & $-0.35^{\mathrm{a}}$ \\
Social function & $-0.24^{\mathrm{a}}$ & $-0.30^{\mathrm{a}}$ & $-0.28^{\mathrm{a}}$ \\
Role emotional & $-0.31^{\mathrm{a}}$ & $-0.39^{\mathrm{a}}$ & $-0.35^{\mathrm{a}}$ \\
Mental health & $-0.28^{\mathrm{a}}$ & $-0.45^{\mathrm{a}}$ & $-0.35^{\mathrm{a}}$ \\
Physical components & $-0.41^{\mathrm{a}}$ & $-0.38^{\mathrm{a}}$ & $-0.44^{\mathrm{a}}$ \\
Mental components & $-0.35^{\mathrm{a}}$ & $-0.48^{\mathrm{a}}$ & $-0.41^{\mathrm{a}}$
\end{tabular}

\footnotetext{
a Correlation is significant at the 0.01 level.

$\mathrm{b}$ Correlation is significant at the 0.05 level.
} 


\begin{tabular}{|c|c|c|}
\hline Symptoms & $\begin{array}{l}\text { Kappa, } \\
\text { Original }\end{array}$ & $\begin{array}{l}\text { Kappa, } \\
\text { Persian }\end{array}$ \\
\hline 1. Constipation & 0.63 & 0.60 \\
\hline 2. Nausea & 0.43 & 0.23 \\
\hline 3. Vomiting & 0.61 & 0.53 \\
\hline 4. Diarrhea & 0.06 & 0.21 \\
\hline 5. Decreased appetite & 0.39 & 0.72 \\
\hline 6. Muscle cramps & 0.34 & 0.79 \\
\hline 7. Swelling in legs & 0.32 & 0.38 \\
\hline 8. Shortness of breath & 0.38 & 0.40 \\
\hline 9. Lightheadedness or dizziness & 0.12 & 0.48 \\
\hline $\begin{array}{l}\text { 10. Restless legs or difficulty keeping } \\
\text { legs still }\end{array}$ & 0.74 & 0.40 \\
\hline 11. Numbness or tingling in feet & 0.63 & 0.75 \\
\hline 12. Feeling tired or lack of energy & 0.50 & 0.90 \\
\hline 13. Cough & 0.47 & 0.67 \\
\hline 14. Dry mouth & 0.40 & 0.31 \\
\hline 15. Bone or joint pain & 0.37 & 0.85 \\
\hline 16. Chest pain & 0.62 & 0.58 \\
\hline 17. Headache & 0.29 & 0.79 \\
\hline 18. Muscle soreness & 0.20 & 0.85 \\
\hline 19. Difficulty concentrating & 0.12 & 0.23 \\
\hline 20. Dry skin & 0.43 & 0.45 \\
\hline 21. Itching & 0.90 & 0.78 \\
\hline 22. Worrying & 0.66 & 0.83 \\
\hline 23. Feeling nervous & 0.58 & 0.88 \\
\hline 24. Trouble falling asleep & 0.63 & 0.93 \\
\hline 25. Trouble staying asleep & 0.79 & 0.85 \\
\hline 26. Feeling irritable & 0.43 & 0.88 \\
\hline 27. Feeling sad & 0.83 & 0.60 \\
\hline 28. Feeling anxious & 0.79 & 0.80 \\
\hline 29. Decreased interest in sex & 0.20 & 0.78 \\
\hline $\begin{array}{l}\text { 30. Difficulty becoming sexually } \\
\text { aroused }\end{array}$ & 0.53 & 0.80 \\
\hline
\end{tabular}

\section{Discussion}

The aim of this study was to assess psychometric properties of the Persian version of DSI. Several studies were conducted to identify prevalence, severity, and overall impact of physical and psychological symptoms. Most of these studies aimed to design intervention studies to reduce symptoms burden and promote QoL (24-26). To recognize such symptoms, a valid and reliable instrument is necessary to enhance assessment of both disease and treatment-related symptoms of hemodialysis patients in research and practice. In this study, DSI was translated based on WHO process of translation and adaptation of instruments. The face and content validity of the ques- tionnaire were confirmed after minor revisions. Yesilbalkan evaluated psychometric properties of the Turkish language version of the DSI and reported a good content validity for the Turkish version of the DSI (27). To establish the convergent validity of the Persian version of DSI, the DSI and SF-36 questionnaires were administered to patients. The study findings revealed significant moderateto-high levels of correlation between the DSI and the SF36 scores with correlation coefficients ranged from 0.18 to 0.48 . The study findings revealed that DSI had a good internal consistency. Cronbach's alpha for total scale of DSI was 0.90. Onsoz et al. reported Cronbach alpha coefficients for the Turkish version of the DSI as 0.83 (27). In this study, test-retest reliability coefficients ranged from 0.21 to 0.93 indicating an acceptable range of stability. Weisbord et al. reported Kappa statistics ranged from 0.06 to 0.90 for original version of the DSI (16). Onsoz et al. reported a range of stability between 0.10 to 0.9 for Turkish version of the DSI (27). Compared to the original version, the Iranian version had better results regarding these domains. In our study, two items had low kappa values including diarrhea and nausea. These results are consistent with some other studies $(16,27)$. The findings of this study suggest that the DSI is a reliable and valid tool to assess physical and psychological symptoms in patients with ESRD. The DSI is easy to understand and respond and takes less than ten minutes to be completed. It can be used for improved management of patient symptoms and is important in the evaluation and clinical care of HD patients. There were some limitations in this study. Non-random sampling and a relatively small sample size restricted the generalizability of study findings. Consequently, it is recommended to perform multicenter or multistate studies with larger sample sizes. Moreover, as we evaluated only the validity and reliability of the DSI, assessing responsiveness of DSI is also recommended.

\section{Acknowledgements}

The researchers express their gratitude to the instrument owner, Steven D. Weisbord and participants in this study as well as the Research Deputy of Qom University of Medical Sciences to fund and support this project.

\section{Authors' Contributions}

Hadi Zamanian designed the study and contributed to the writing process. Zahra Taheri was the main investigator, collected data, and wrote the first draft. All authors read and approved the paper.

\section{Funding/Support}

Research Deputy of Qom University of Medical Sciences funded and supported this project.

\section{References}

1. Bayoumi M, Al Harbi A, Al Suwaida A, Al Ghonaim M, Al Wakeel J, Mishkiry A. Predictors of quality of life in hemodialysis patients. 
Saudi J Kidney Dis Transpl. 2013:24(2):254-9.

2. Abdel-Kader K, Unruh ML, Weisbord SD. Symptom burden, depression, and quality of life in chronic and end-stage kidney disease. Clin J Am Soc Nephrol. 2009;4(6):1057-64.

3. Weisbord SD, Bossola M, Fried LF, Giungi S, Tazza L, Palevsky PM, et al. Cultural comparison of symptoms in patients on maintenance hemodialysis. Hemodial Int. 2008;12(4):434-40.

4. Biniaz V, Tayybi A, Nemati E, Sadeghi Shermeh M, Ebadi A. Different aspects of fatigue experienced by patients receiving maintenance dialysis in hemodialysis units. Nephrourol Mon. 2013;5(4):897-900.

5. Murtagh FE, Addington-Hall J, Higginson IJ. The prevalence of symptoms in end-stage renal disease: a systematic review. Adv Chronic Kidney Dis. 2007;14(1):82-99.

6. Davison SN. Pain in hemodialysis patients: prevalence, cause, severity, and management. Am J Kidney Dis. 2003;42(6):1239-47.

7. Almutary H, Bonner A, Douglas C. Symptom burden in chronic kidney disease: a review of recent literature. J Ren Care. 2013;39(3):140-50.

8. Weisbord SD, Fried LF, Arnold RM, Fine MJ, Levenson DJ, Peterson RA, et al. Prevalence, severity, and importance of physical and emotional symptoms in chronic hemodialysis patients. J Am Soc Nephrol. 2005;16(8):2487-94.

9. Taheri Kharame Z, Zamanian H, Foroozanfar S, Afsahi S. Religious wellbeing as a predictor for quality of life in Iranian hemodialysis patients. Glob J Health Sci. 2014;6(4):34855.

10. Rostami Z, Einollahi B, Lessan-Pezeshki M, Soleimani Najaf Abadi A, Mohammadi Kebar S, Shahbazian H, et al. Health-related quality of life in hemodialysis patients: an Iranian multi-center study. Nephrourol Mon. 2013;5(4):901-12.

11. Edalat-Nejad M, Qlich-Khani M. Quality of life and sleep in hemodialysis patients. Saudi J Kidney Dis Transpl. 2013;24(3):514-8.

12. Davison SN, Jhangri GS. Impact of pain and symptom burden on the health-related quality of life of hemodialysis patients. J Pain Symptom Manage. 2010;39(3):477-85.

13. Yong DS, Kwok AO, Wong DM, Suen MH, Chen WT, Tse DM. Symptom burden and quality of life in end-stage renal disease: a study of 179 patients on dialysis and palliative care. Palliat Med. 2009;23(2):111-9.

14. Thong MS, van Dijk S, Noordzij M, Boeschoten EW, Krediet RT, Dekker FW, et al. Symptom clusters in incident dialysis patients: associations with clinical variables and quality of life. Nephrol Dial Transplant. 2009;24(1):225-30.

15. Berman N, Christianer K, Roberts J, Feldman R, Reid MC, Shenge- lia R, et al. Disparities in symptom burden and renal transplant eligibility: a pilot study. J Palliat Med.2013;16(11):1459-65.

16. Weisbord SD, Fried LF, Arnold RM, Rotondi AJ, Fine MJ, Levenson DJ, et al. Development of a symptom assessment instrument for chronic hemodialysis patients: the Dialysis Symptom Index. $J$ Pain Symptom Manage. 2004;27(3):226-40.

17. Weisbord SD, Fried LF, Unruh ML, Kimmel PL, Switzer GE, Fine MJ, et al. Associations of race with depression and symptoms in patients on maintenance haemodialysis. Nephrol Dial Transplant. 2007;22(1):203-8.

18. Ramer S, Germain A, Dohar S, Unruh M. Event-related distress in kidney disease patients. Nephrol Dial Transplant. 2012;27(1):299-303.

19. Ware JE, Jr., Gandek B. Overview of the SF-36 Health Survey and the International Quality of Life Assessment (IQOLA) Project. $J$ Clin Epidemiol.1998;51(11):903-12.

20. Montazeri A, Goshtasebi A, Vahdaninia M, Gandek B. The Short Form Health Survey (SF-36): translation and validation study of the Iranian version. Qual Life Res. 2005;14(3):875-82.

21. Gandek B, Ware JJ. Methods for validating and norming translations of health status questionnaires: the IQOLA Project approach. International Quality of Life Assessment. J Clin Epidemiol. 1998;51(11):953-9.

22. Fitzner K. Reliability and validity: a quick review. Diabetes Educ. 2007;33(5):775-6.

23. de Boer MR, Moll AC, de Vet HC, Terwee CB, Volker-Dieben HJ, van Rens GH. Psychometric properties of vision-related quality of life questionnaires: a systematic review. Ophthalmic Physiol Opt. 2004;24(4):257-73.

24. Weisbord SD, Mor MK, Green JA, Sevick MA, Shields AM, Zhao $\mathrm{X}$, et al. Comparison of symptom management strategies for pain, erectile dysfunction, and depression in patients receiving chronic hemodialysis: a cluster randomized effectiveness trial. Clin J Am Soc Nephrol. 2013;8(1):90-9.

25. Kim KH, Kim TH, Kang JW, Sul JU, Lee MS, Kim JI, et al. Acupuncture for symptom management in hemodialysis patients: a prospective, observational pilot study. J Altern Complement Med. 2011;17(8):741-8.

26. Weisbord SD, Shields AM, Mor MK, Sevick MA, Homer M, Peternel J, et al. Methodology of a randomized clinical trial of symptom management strategies in patients receiving chronic hemodialysis: the SMILE study. Contemp Clin Trials. 2010;31(5):491-7.

27. Onsoz HB, Usta Yesilbalkan O. Reliability and Validity of the Turkish Version of the Dialysis Symptom Index in Chronic Hemodialysis Patients. Turk Nephrol Dial Transplant. 2013;22(1):60-7. 